\title{
Competência leitora nas bibliotecas escolares
}

\author{
Kelley Cristine Gonçalves Dias Gasque \\ Doutora; Universidade de Brasília, Brasília, DF, Brasil; \\ kelleycristinegasque@hotmail.com \\ Flor De María Silvestre \\ Doutoranda; Universidade de Brasília, Brasília, DF, Brasil; \\ silvestreestela@gmail.com
}

\begin{abstract}
Resumo: $\mathrm{O}$ artigo analisa a contribuição dos projetos de leitura das bibliotecas escolares, das escolas que obtiveram os primeiros lugares no ranking do Enem, de 2013, no Distrito Federal. Os objetivos específicos são descrição da proposta pedagógica e da estrutura das escolas; descrição da estrutura, dos produtos e dos serviços oferecidos pelas bibliotecas escolares; identificação dos projetos de leitura e contribuição para o desenvolvimento de competências leitoras; e, por fim, identificação da relação entre docente e bibliotecário nos projetos de leitura. A metodologia tem natureza quali-quantitativa. A amostra abrangeu seis escolas, sendo três privadas e três públicas. Os resultados mostram que os projetos de leitura vinculados às disciplinas lecionadas pelos professores pesquisados, em geral, são realizados sem participação das bibliotecas escolares. Contudo, os professores relataram que as bibliotecas escolares contribuíram para os resultados do Enem em outros aspectos, tais como oferta de acesso à informação organizada, horário de atendimento adequado e recursos humanos.
\end{abstract}

Palavras-chave: Biblioteca escolar. Centro de recurso de aprendizagem. Leitura. Competências leitoras. Enem.

\section{Introdução}

Vive-se em uma época em que a tecnologia e a informação transformam processos, serviços e pensamentos de forma acelerada. $\mathrm{O}$ aprender situa-se no núcleo da sociedade, por isso, pesquisadores como Pozo (2004) e Gasque (2012) denominam-na sociedade da aprendizagem. Essa sociedade exige certas competências dos cidadãos, dentre elas, o letramento informacional - processo necessário para que eles possam avaliar, interpretar, utilizar informação e gerar conhecimento ao longo da vida. Perpassando esse processo, a leitura constitui-se como uma das competências cruciais a serem desenvolvidas.

Apesar de reconhecidamente a leitura ser instrumento importante na sociedade contemporânea, os resultados das avaliações realizadas por estudantes 
brasileiros mostram que os estudantes não apresentam desempenho satisfatório em relação à escrita e à leitura. Na edição do Exame Nacional do Ensino Médio (Enem), de 2014, por exemplo, 250 candidatos tiraram a nota máxima equivalente a 1.000 pontos, outros 529.374 tiraram zero na redação. Os resutados revelam que os jovens têm pouca prática na leitura e escrita (BRASIL, 2015).

Nesse sentido, as bibliotecas escolares atuantes como Centro de Recursos de Aprendizagem podem, com a mediação dos bibliotecários, desenvolver projetos de incentivo à leitura. A parceria com os docentes da comunidade escolar pode melhorar a competências leitora e a aprendizagem dos estudantes.

O objetivo da pesquisa foi analisar a contribuição da biblioteca escolar nas escolas que obtiveram os melhores desempenhos na avaliação do Enem, considerando, especificamente, os projetos de leitura. Para tanto, foram considerados os objetivos específicos: descrição da proposta pedagógica e das estruturas das escolas pesquisadas; descrição da estrutura, dos produtos e dos serviços oferecidos pela biblioteca escolar das escolas pesquisadas; identificação dos projetos de leitura e a contribuição da biblioteca escolar para a formação de competências leitoras, e, por fim, identificação da relação entre o docente e o bibliotecário nos projetos de leitura. Para a pesquisa, foram selecionadas seis escolas, três privadas e três públicas, que obtiveram os primeiros lugares no ranking do Exame Nacional do Ensino Médio de 2013. Os principais tópicos tratados na revisão de literatura foram leitura, competência leitora e bibliotecas atuantes como Centro de Recursos de Aprendizagem.

\section{Competência leitora}

Ao considerar os aspectos cognitivos do sujeito e a interação com o ambiente em que se vive, reconhece-se que a vida, na sociedade contemporânea, traz novos desafios, em especial, em relação à informação e ao conhecimento. Para lidar com eles, o processo de letramento informacional (LI) torna-se fundamental, visto que possibilita o desenvolvimento de competências para buscar e usar a informação para resolução de problemas ou tomada de decisões. 
Assim, pode ser caracterizado como um processo que propicia a aprendizagem ativa, independente, bem como o pensamento reflexivo e o aprender a aprender ao longo da vida (GASQUE, 2010).

Gasque (2010), no artigo intitulado Arcabouço conceitual do letramento informacional distingue letramento informacional do termo competência. Competência refere-se às habilidades, ferramentas e saberes prévios ativados ao longo de todo processo de letramento informacional. Igualmente, propõe que “[...] competência seja utilizada como expressão do 'saber fazer', derivada das relações entre o conhecimento que o sujeito detém, a experiência adquirida pela prática e a reflexão sobre a ação." (GASQUE, COSTA, 2003, p. 10).

Nesse contexto, a leitura deve ser compreendida como uma das competências informacionais a ser desenvolvida por meio do ensino de estratégias de leituras, considerando os saberes prévios ou conhecimento de mundo que o leitor ativa na hora de interpretar a informação. As competências leitoras requerem gestão de habilidades e estratégias que permitem compreender e interpretar um texto, com o objetivo de transformar informação em conhecimento.

Para Solé (2012), as competências de leitura são desenvolvidas ao longo da vida. A autora ressalta, ainda, que formar leitores equivale a formar cidadãos que possam usar a leitura para obtenção de vários objetivos. Esses leitores devem compreender como ocorre o ato de ler e como fazê-lo para resolver problemas no cotidiano.

De acordo com o documento divulgado pelo Exame Nacional do Ensino Médio, “[...] competências são as modalidades estruturais da inteligência, ou melhor, ações e operações que utilizamos para estabelecer relações com e entre objetos, situações, fenômenos e pessoas que desejamos conhecer." (BRASIL, 2002, p. 11). Por sua vez, de acordo com Solé (2012), compreendem-se as competências leitoras como a capacidade de construir significados a partir do que se lê, dos objetivos, do nível e dos tipos de leitura. Assim, a competência vincula-se à ideia de saber usar as estratégias de leitura necessárias no momento adequado. 


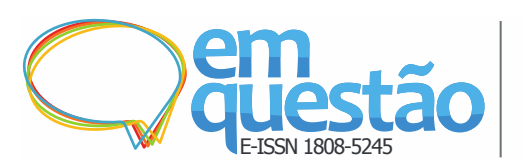

É importante que o leitor, especialmente o estudante em formação no processo educacional básico, encontre sentido nas leituras e conheça diversos tipos de estratégias para serem aplicadas em cada contexto de leitura. Sobre isso, Solé (2004, p. 37) afirma que: “[...] conhecer variadas estratégias que promovam a compreensão e abordar as tarefas de leitura que exijam utilizá-las é chave para fomentar a leitura compreensiva, crítica e epistêmica.".

As referidas estratégias podem ser divididas em três espaços do tempo: "antes da leitura", "durante a leitura", "depois da leitura". O Quadro 1 apresenta as estratégias de leitura nas três fases, de acordo com Solé (2004) e Moreno (2009).

Quadro 1 - Estratégias de leitura

\begin{tabular}{|c|c|c|}
\hline & Solé (2004) & Moreno (2009) \\
\hline ANTES & $\begin{array}{l}\text { Estratégias que permitem } \\
\text { dotar-se de objetivos de } \\
\text { leitura e atualizar os } \\
\text { conhecimentos prévios } \\
\text { relevantes. }\end{array}$ & $\begin{array}{l}\text { - Fazer inferências com o título: o que } \\
\text { disse? O que sugere? } \\
\text { Relacionar o título com o possível } \\
\text { conteúdo. } \\
\text { - Formular hipóteses. } \\
\text { - } \text { Ativar conhecimentos prévios. } \\
\text { - } \text { Ensinar o vocabulário necessário. } \\
\text { - Precisar como ler. Sublinhar. } \\
\text { - Constatar a estrutura de textos } \\
\text { mediante diagramas. }\end{array}$ \\
\hline DURANTE & $\begin{array}{l}\text { Fazer inferências de diferentes } \\
\text { tipos, revisar e comprovar a } \\
\text { própria compreensão durante } \\
\text { o ato de ler e tomar decisões } \\
\text { certeiras ante os erros e as } \\
\text { falhas na compreensão. }\end{array}$ & $\begin{array}{l}\text { - } \quad \text { Reler mediante perguntas explícitas e } \\
\text { inferenciais. } \\
\text { - } \quad \text { Revisar o conteúdo. } \\
\text { - } \quad \text { Modificar ou confirmar hipóteses. } \\
\text { - } \quad \text { Aclarar dúvidas de léxico e expressões. } \\
\text { Avaliar o conteúdo e a forma do texto. }\end{array}$ \\
\hline DEPOIS & $\begin{array}{l}\text { Recapitular o conteúdo, } \\
\text { resumi-lo e ampliar o } \\
\text { conhecimento mediante a } \\
\text { leitura realizada. }\end{array}$ & $\begin{array}{ll}\text { - } & \text { Fazer perguntas literais. } \\
\text { - } & \text { Gerar inferências lógicas. } \\
\text { - } & \text { Gesumir e sintetizar. } \\
\text { Generalizar o conhecimento. }\end{array}$ \\
\hline
\end{tabular}

Fonte: Adaptado de Solé (2004); Moreno (2009).

O domínio dessas estratégias melhora a aprendizagem, além de formar leitores críticos e autônomos. No entanto, os resultados de algumas avaliações realizadas por estudantes brasileiros, em especial o Exame Nacional do Ensino 
Médio, mostram que os jovens brasileiros estão longe de dominarem as estratégias de leitura (BRASIL, 2015).

Os resultados do exame relacionam-se a diversos fatores, como a renda familiar dos candidatos, a proposta pedagógica, a estrutura curricular, dentre outros aspectos importantes. Nesse sentido, a leitura pode se constituir em um dos fatores de avanço, visto que melhora o desempenho de estudantes, como se observa pela literatura, por exemplo, Freire (2003), Solé (2004), dentre outros.

A esse respeito, Carvalho (2008) afirma que a escola não forma estudantes críticos e reflexivos, pois o ensino de leitura baseia-se na decodificação e no ensino de uma gramática descontextualizada. Problemas na formação leitora influenciam, em especial, a vida acadêmica dos estudantes. Quaglia, Bonnici e Paixão (2015), em uma pesquisa com estudantes nos anos iniciais de graduação, mostram que eles leem pouco e apresentam dificuldades na produção textual.

Sobre isso, a escola deveria ser responsável, em grande parte, pela formação de leitores críticos. Contudo, a família e as bibliotecas escolares e públicas não podem se omitir como colaboradores nesse processo. As bibliotecas podem se constituir recursos importantes na formação dos leitores se houver investimentos na infraestrutura e trabalho de integração entre docentes e bibliotecários no processo de aprendizagem. Por isso, é necessário mudar de uma concepção de biblioteca escolar como depositária de livros para uma biblioteca dinâmica, atuante como Centro de Recursos de Aprendizagem (GASQUE, 2012).

\section{Biblioteca Escolar atuante como Centro de Recursos de Aprendizagem}

As diferentes estratégias de leituras usadas no processo da compreensão leitora são, comumente, desenvolvidas em salas de aula por alguns professores, mas a biblioteca escolar atuante como Centro de Recursos de Aprendizagem também pode promover competências e estratégias leitoras por meio de projetos de leituras mediados por bibliotecários e, em parceria com os professores. De acordo com o Centro Regional para o Fomento do Livro na América Latina e no 
Caribe (2007), a biblioteca escolar constitui-se o melhor lugar para promover as competências informacionais e leitoras.

Diante disso, as bibliotecas escolares precisam trabalhar de forma integrada à proposta pedagógica da escola, como Centro de Recursos de Aprendizagem (GASQUE, 2012). O Quadro 2 apresenta as diferenças entre os paradigmas da biblioteca escolar tradicional e da atuante como Centro de Recursos de Aprendizagem.

Quadro 2 - Paradigmas da biblioteca escolar

\begin{tabular}{|c|c|}
\hline Biblioteca escolar tradicional - BE & Centro de Recursos de Aprendizagem - CRA \\
\hline $\begin{array}{l}\text { - } \text { Paradigma da preservação. } \\
\text { - } \quad \text { Foco no acesso à informação. } \\
\text { - Centrado na transmissão de } \\
\text { conhecimento. } \\
\text { - Armazenamento de livros. } \\
\text { - Animação da leitura. }\end{array}$ & $\begin{array}{l}\text { - } \text { Paradigma da integração pedagógica. } \\
\text { - } \quad \text { Espaços multiusos. } \\
\text { - } \text { Favorecimento da socialização. } \\
\text { - } \quad \text { Centrado no letramento informacional. } \\
\text { - } \text { Acesso aos diferentes pontos de vistas dos } \\
\text { - } \quad \text { Instrumento de desenvolvimento do currículo. } \\
\text { - } \quad \text { Fomento à leitura e à pesquisa cientifica. } \\
\text { - } \quad \text { Caráter pedagógico e cultural. } \\
\text { - } \quad \text { Apoio à formação continuada } \\
\text { - } \quad \text { Estrutura adequada, Layout funcional. } \\
\text { - Uso de TIC's. }\end{array}$ \\
\hline
\end{tabular}

Fonte: Gasque (2013).

O ponto principal, apresentado no quadro 2, relaciona-se à compreensão do conceito de Centro de Recursos de Aprendizagem que, por sua vez, deve estar vinculado à proposta pedagógica da escola. Para Gasque (2013), o paradigma de integração pedagógica não exclui o paradigma de acesso à informação, visto que o Centro de Recursos de Aprendizagem requer, também, a gestão da informação. A autora argumenta que a organização e os serviços do Centro de Recursos de Aprendizagem devem ser concebidos com o objetivo de contribuir para o desenvolvimento das competências básicas dos estudantes, em que o acesso à informação e o uso dela são os passos prévios para a produção de conhecimentos.

O manifesto da Federação Internacional das Associações e Instituições Bibliotecárias e da Organização das Nações Unidas para a Educação, Ciência e Cultura sobre biblioteca escolar situa a biblioteca escolar no paradigma de integração pedagógica. Argumenta que a função da biblioteca escolar é ajudar a 
desenvolver competências para o aprendizado contínuo dos estudantes, bem como favorecer a imaginação e formar cidadãos críticos e responsáveis, por meio da leitura (INTERNATIONAL FEDERATION OF LIBRARY ASSOCIATIONS AND INSTITUTIONS, 2000). Portanto, a biblioteca escolar deve estar integrada ao processo educativo e promover a leitura e o uso de recursos informativos.

As políticas em prol do livro, da leitura e da biblioteca escolar, na América Latina, apontam para a formação e a capacitação dos profissionais que trabalham com essas temáticas, como professores, bibliotecários, animadores culturais, etc. Santos (2009) e Naranjo (2005) destacam a necessidade de melhorar os índices de leitura por meio da formação continuada de pessoas capacitadas para atuarem como mediadores. Para tanto, a formação de mediadores deve passar pela aquisição da compreensão dos processos de leitura, dos tipos de leitura, das estratégias de leitura e dos aspectos políticos e culturais que influenciam na formação de leitores.

\section{Referencial teórico}

O referencial teórico da pesquisa fundamenta-se nas relações entre os conceitos de Biblioteca atuante como Centro de Recurso de Aprendizagem, competências leitoras e competência informacional. Parte-se do pressuposto que o desenvolvimento da competência leitora no processo de letramento informacional, realizada nas bibliotecas escolares, em parceria com os docentes, influencia positivamente a aprendizagem dos estudantes. Assim, a biblioteca escolar constitui-se espaço de aprendizagem, lazer e cultura que agrega as competências do bibliotecário, que participa ativamente da promoção de atividades de estímulo à leitura, por meio do trabalho compartilhado com os docentes e com a comunidade escolar, como se observa na Figura 1. 
Figura 1 - Referencial teórico

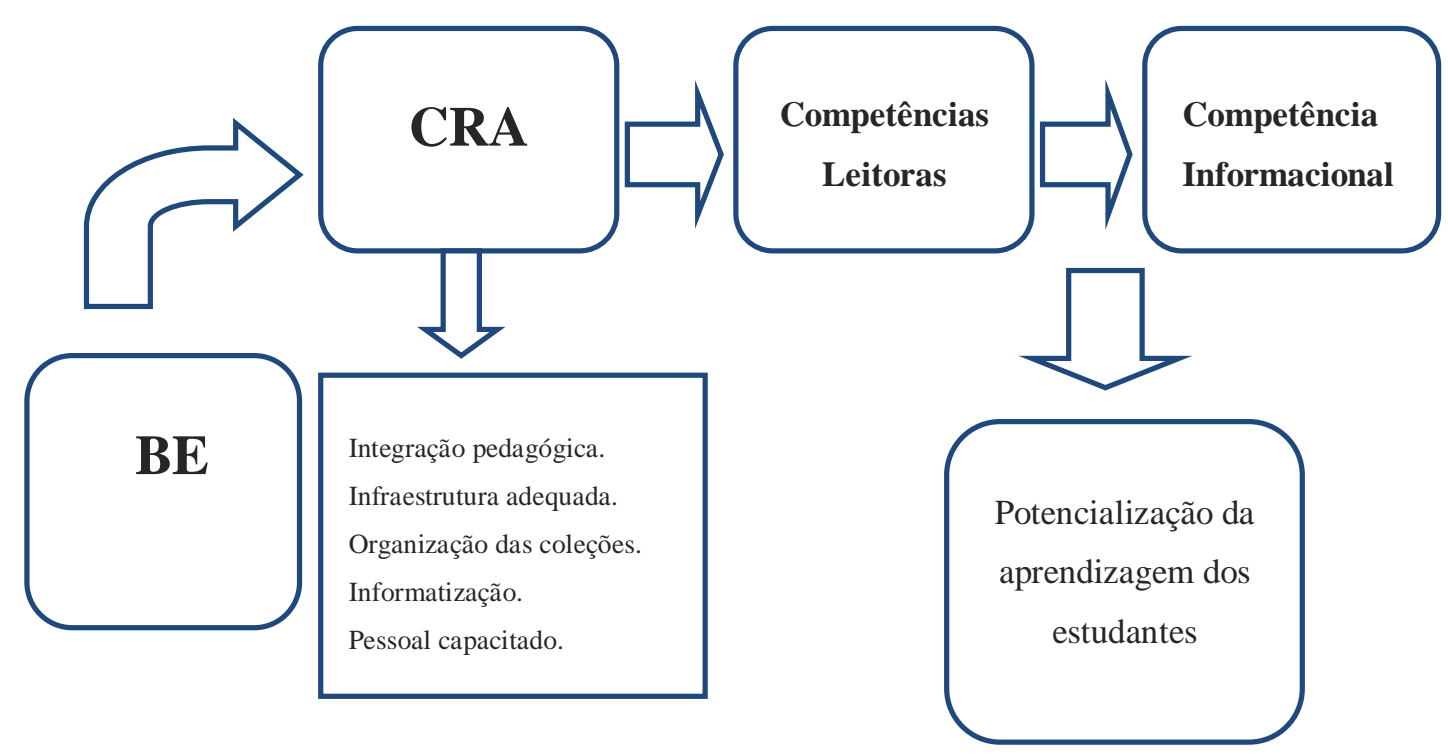

Fonte: Elaborado pelas autoras.

\section{Metodologia}

A metodologia da pesquisa foi composta pela descrição da pesquisa, pelo instrumento de coleta de dados e pela caracterização da amostra. A pesquisa é quali-quantitativa, com o objetivo de identificar a natureza da realidade, o sistema de relações conceituais e a estrutura dinâmica do contexto.

A amostragem foi composta por seis bibliotecas das primeiras escolas do ranking do Exame Nacional do Ensino Médio de 2013 - três públicas e três privadas. A coleta de dados dividiu-se em três partes. Na primeira fase, realizouse a análise documental da escola, mediante informações obtidas dos sites dos colégios, da publicidade impressa e de documentos divulgados pelos colégios. Por esses materiais, foram identificadas informações acerca do projeto pedagógico e dos projetos extracurriculares.

$\mathrm{Na}$ segunda parte, ocorreu a avaliação da biblioteca escolar, por meio de formulário produzido pelo Conselho Federal de Biblioteconomia e pelo Grupo de Estudos em Biblioteca Escolar da Escola de Ciência da Informação da Universidade Federal de Minas Gerais (CAMPELLO, 2010). O formulário, composto de 89 questões sobre estrutura, produtos, serviços e recursos humanos, foi aplicado entre outubro e novembro de 2014 aos funcionários da biblioteca, todos com curso superior, mas somente três bacharéis em Biblioteconomia, isto é, metade da amostra. O processo demorou em média 3 horas e foi 
acompanhado por uma das pesquisadoras. Em seguida, a pesquisadora realizou duas perguntas relacionadas à questão da leitura: (1) Desenvolvem atividades que promovem as competências leitoras? (2) Como é o trabalho de integração com os docentes? A aplicação das perguntas demorou em média 20 minutos. As respostas foram anotadas por tópicos, em um bloco de notas e, posteriormente, tabuladas.

A terceira parte constou da aplicação de questionários aos docentes que trabalham em projetos de leitura. Anteriormente, o pré-teste do questionário foi realizado no dia 27/09/2014, com uma professora do ensino médio e duas do ensino fundamental, e, em seguida, foram realizados pequenos ajustes.

\section{Análise dos resultados}

A análise dos resultados ocorreu a partir dos objetivos específicos, quais sejam: descrição da proposta pedagógica e das estruturas das escolas pesquisadas; descrição da estrutura, dos produtos e dos serviços oferecidos pela biblioteca escolar das escolas pesquisadas; identificação dos projetos de leitura e a contribuição da biblioteca escolar para a formação de competências leitoras, e, por fim, identificação da relação entre o docente e o bibliotecário nos projetos de leitura. As escolas pesquisadas foram designadas como C1, C2, C3 - escolas privadas, e C4, C5 e C6 - escolas públicas.

\subsection{Estrutura e proposta pedagógica dos colégios pesquisados}

As escolas pesquisadas, em geral, apresentam boa infraestrutura, espaços adequados para estudar, espaços para lazer, segurança e limpeza adequada. Contudo, houve diferença, no que tange ao acesso às tecnologias da informação e comunicação, isto é, os colégios particulares, diferentemente dos públicos, contam com tecnologia de última geração. Apesar de inúmeras dificuldades em relação à infraestrutura, materiais e capacitação, os colégios públicos pesquisados programavam atividades de aprendizagem por meio de projetos interdisciplinares que estimulam o pensamento crítico dos estudantes. Projetos que poderiam ter resultados diferenciados com uma biblioteca mais atuante.

A concepção pedagógica dos colégios pesquisados foi analisada, considerando a leitura e a configuração da biblioteca escolar. Os documentos 
das escolas mostram que os projetos político-pedagógicos estão desenhados de acordo com a abordagem construtivista com enfoque social, na qual o estudante é protagonista do próprio processo de aprendizagem, a partir de uma concepção pessoal e coletiva na aquisição de novos conhecimentos (GALLARDO, 2007).

Gasque (2013) argumenta que a concepção pedagógica da escola contribui para o êxito da nova concepção de biblioteca escolar. Isso porque escolas com currículos flexíveis que incentivam atividades de resolução de problemas requerem uma biblioteca mais dinâmica e integrada ao projeto educacional. Em relação às escolas pesquisadas, apesar de apresentarem uma proposta pedagógica relativamente atual, os relatos mostram que as aulas ainda são mais tradicionais do que inovadoras.

\subsection{Estrutura, produtos e serviços oferecidos pela biblioteca escolar das escolas pesquisadas}

Os padrões da avaliação das bibliotecas escolares do Grupo de Estudos em Biblioteca Escolar da Universidade Federal de Minas Gerais (CAMPELLO, 2010) permitiram criar um panorama completo da realidade das bibliotecas escolares pesquisadas, em relação aos itens: infraestrutura, serviços, coleção, tecnologia e pessoal. E, ainda, forneceram critérios para avaliação desses itens.

No que concerne ao espaço físico, buscou-se identificar as condições de iluminação, ventilação, limpeza, estética, acessibilidade e segurança, de acordo com as condições (B) boas; (M) médias e (R) ruins, além das metas de melhoria. Os colégios C1, C2 e C4 têm boas condições nos itens mencionados. Em termos de estética, a biblioteca do colégio C3 foi o pior colégio avaliado. Considerando todos os itens, a biblioteca do colégio C6 apresenta as piores condições. Além disso, essa biblioteca juntamente com a biblioteca do colégio C5 foram as únicas que não apresentaram metas de melhoria por não terem previsão de investimento.

Em relação à estrutura, as bibliotecas escolares situadas no nível exemplar são as que apresentam assentos suficientes para acomodar simultaneamente uma classe inteira, usuários avulsos e grupos de estudantes; um balcão de atendimento; e ambiente específico para atividades técnicas, com uma 
mesa, uma cadeira e um computador com acesso à internet. Destaca-se que foi necessário acrescentar o nível zero para as bibliotecas que não cumpriram os requisitos do padrão básico. Com base nos dados registrados nos formulários, as bibliotecas pesquisadas foram avaliadas como:

Quadro 3 - Avaliação estrutural das bibliotecas escolares

\begin{tabular}{|l|l|l|l|l|l|}
\hline C1 & C2 & C3 & C4 & C5 & C6 \\
\hline $\begin{array}{l}\text { Nível } \\
\text { básico }\end{array}$ & $\begin{array}{l}\text { Nível } \\
\text { básico }\end{array}$ & $\begin{array}{l}\text { Nível } \\
\text { básico }\end{array}$ & $\begin{array}{l}\text { Nível } \\
\text { exemplar }\end{array}$ & Nível Zero & Nível Zero \\
\hline
\end{tabular}

Fonte: Elaborada pelas autoras.

De acordo as respostas dos formulários, só a biblioteca do colégio $\mathrm{C} 4$ cumpre todos os critérios. As bibliotecas dos colégios C2 e C3 encontram-se no nível básico, pois têm assentos suficientes para acomodar simultaneamente uma classe inteira; um balcão de atendimento, uma mesa, uma cadeira e um computador com acesso à internet. Os colégios C1, C5, C6 não cumprem com nenhum dos critérios propostos pelos padrões. As bibliotecas dos colégios C5 e C6 não têm computadores, nem acesso à internet. A biblioteca do colégio C1 tem computador, mas não tem espaço para acomodar uma classe inteira.

Em suma, somente uma biblioteca possui o nível exemplar e três não se enquadram nem no nível básico. Uma estrutura adequada é importante para que as bibliotecas tenham condições de oferecer bons serviços e produtos. Sobre isso, destaca-se:

O conceito de biblioteca escolar atuante como Centro de Recursos de Aprendizagem é fundamental para se ter uma abordagem sistêmica e integrada à comunidade educacional. Nessa abordagem, a estrutura (arquitetura, layout, mobiliários, recursos e produtos) constitui-se elemento fundamental (GASQUE, 2013, p. 8).

Em relação aos computadores com acesso à internet, para uso de professores e estudantes, as bibliotecas dos colégios C2, C3 e C4 apresentam computadores conectados à internet para a busca de informação; os colégios C3 e C4 não forneceram dados sobre a relação entre computadores e estudantes. As bibliotecas dos colégios, C1, C5 e C6 não possuem computador para uso dos estudantes. Diante disso, os últimos colégios mencionados, de acordo os padrões 
do Grupo de Estudos em Biblioteca Escolar (CAMPELLO, 2010), não se encontram em nenhum nível, por isso foram avaliados como nível zero. Os colégios C2, C3 e C4 encontram-se no nível básico, compreendidos como aqueles que possuem no mínimo um computador conectado à internet para uso dos usuários (CAMPELLO, 2010).

Quadro 4 - Avaliação da quantidade de computadores disponíveis nas bibliotecas escolares

\begin{tabular}{|l|l|l|l|l|l|}
\hline C1 & C2 & C3 & C4 & C5 & C6 \\
\hline Nível zero & $\begin{array}{l}\text { Nível } \\
\text { básico }\end{array}$ & $\begin{array}{l}\text { Nível } \\
\text { básico }\end{array}$ & $\begin{array}{l}\text { Nível } \\
\text { básico }\end{array}$ & $\begin{array}{l}\text { Nível } \\
\text { zero }\end{array}$ & Nível zero \\
\hline
\end{tabular}

Fonte: Elaborado pelas autoras.

O documento Diretrizes para Bibliotecas Escolares menciona que as bibliotecas escolares devem incluir no orçamento e no planejamento recursos eletrônicos como acesso à internet, bases de dados e software educativo (INTERNATIONAL FEDERATION OF LIBRARY ASSOCIATIONS AND INSTITUTIONS, 2002). Para Kuhthau (1999), os computadores conectados à internet permitem ampliar o acesso à informação para uma vasta coleção disponível na rede. Além disso, ressalta que a aprendizagem desses recursos pode ser potencializada pela mediação dos bibliotecários em parceria com os professores.

No que concerne à organização do acervo, de acordo com os padrões do Grupo de Estudos em Biblioteca Escolar da Universidade Federal de Minas Gerais (CAMPELLO, 2010), as bibliotecas avaliadas no nível básico devem incluir pelo menos os livros do acervo no catálogo impresso, a fim de permitir a recuperação por autor, título e assunto. No nível exemplar, a biblioteca escolar deve possibilitar não só o acesso remoto aos itens do acervo, bem como a recuperação por outros pontos de acesso. As bibliotecas dos colégios C5 e C6 não possuem os requisitos mínimos para o nível básico, pois não têm computadores, nem base de dados que permitem o acesso rápido à informação. As bibliotecas dos colégios $\mathrm{C} 1, \mathrm{C} 2, \mathrm{C} 3$ e $\mathrm{C} 4$ contam com catálogo informatizado com acesso remoto ao acervo, portanto, foram avaliadas como exemplares nesse critério. 


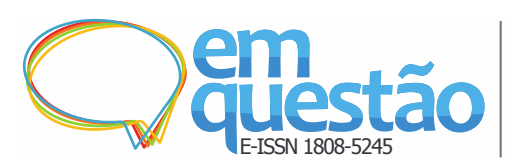

Quadro 5 - Avaliação da organização do acervo das bibliotecas escolares

\begin{tabular}{|l|l|l|l|l|l|}
\hline C1 & C2 & C3 & C4 & C5 & C6 \\
\hline $\begin{array}{l}\text { Nível } \\
\text { exemplar }\end{array}$ & $\begin{array}{l}\text { Nível } \\
\text { exemplar }\end{array}$ & $\begin{array}{l}\text { Nível } \\
\text { exemplar }\end{array}$ & $\begin{array}{l}\text { Nível } \\
\text { exemplar }\end{array}$ & Nível Zero & Nível zero \\
\hline
\end{tabular}

Fonte: Elaborado pelas autoras.

Em relação ao acervo, os padrões do Grupo de Estudos em Biblioteca Escolar da Universidade Federal de Minas Gerais (CAMPELLO, 2010) consideram que as bibliotecas no nível exemplar têm no mínimo quatro títulos por estudante. No nível básico, requer-se, pelo menos, um livro por estudante. Os padrões destacam para os dois níveis que, além de livros, a biblioteca escolar deve contar com revistas e outros materiais não impressos, tais como: documentos sonoros, visuais e digitais. As seis bibliotecas pesquisadas, nesse quesito, apresentam nível exemplar. Os dados podem ser observados a seguir:

\begin{tabular}{|l|l|l|l|l|l|}
\multicolumn{5}{c}{ Quadro 6 - Avaliação quantitativa do acervo das bibliotecas escolares } \\
\hline C1 & C2 & C3 & C4 & C5 & C6 \\
\hline $\begin{array}{l}\text { Nível } \\
\text { exemplar }\end{array}$ & $\begin{array}{l}\text { Nível } \\
\text { exemplar }\end{array}$ & $\begin{array}{l}\text { Nível } \\
\text { exemplar }\end{array}$ & $\begin{array}{l}\text { Nível } \\
\text { exemplar }\end{array}$ & $\begin{array}{l}\text { Nível } \\
\text { exemplar }\end{array}$ & $\begin{array}{l}\text { Nível } \\
\text { exemplar }\end{array}$ \\
\hline
\end{tabular}

Destaca-se que o acervo foi avaliado quantitativamente e não qualitativamente. De acordo com Hopkins (1999), considera-se o acervo da biblioteca fundamental para o desenvolvimento do ensino-aprendizagem. A plena utilização da biblioteca escolar vincula-se, em grande parte, ao acesso às informações atualizadas e precisas, de boa qualidade e em quantidade suficiente, que deem apoio ao currículo. Para tanto, requer desenvolver programas de formação profissional para que os professores possam colaborar na seleção de materiais.

Sobre os serviços oferecidos pelas bibliotecas escolares, para o nível básico, de acordo com os padrões do Grupo de Estudos em Biblioteca Escolar da Universidade Federal de Minas Gerais (CAMPELLO, 2010), as bibliotecas precisam oferecer consulta no local, empréstimo domiciliar, atividades de incentivo à leitura e orientação à pesquisa. Para o nível exemplar, devem oferecer consulta no local, empréstimo domiciliar, atividades de incentivo à 
leitura e orientação à pesquisa, além de serviço de divulgação de novas aquisições, exposições e serviços específicos para os professores, tais como levantamento bibliográfico e boletim de alerta. Considerando os referidos padrões, as seis escolas pesquisadas foram avaliadas no nível básico.

Quadro 7 - Avaliação dos serviços oferecidos pelas bibliotecas escolares

\begin{tabular}{|l|l|l|l|l|l|}
\hline C6 & C5 & C4 & C3 & C2 & C1 \\
\hline $\begin{array}{l}\text { Nível } \\
\text { básico }\end{array}$ & $\begin{array}{l}\text { Nível } \\
\text { básico }\end{array}$ & $\begin{array}{l}\text { Nível } \\
\text { básico }\end{array}$ & $\begin{array}{l}\text { Nível } \\
\text { básico }\end{array}$ & $\begin{array}{l}\text { Nível } \\
\text { básico }\end{array}$ & $\begin{array}{l}\text { Nível } \\
\text { básico }\end{array}$ \\
\hline
\end{tabular}

Fonte: Elaborado pelas autoras.

Em relação aos serviços, as bibliotecas escolares dos colégios privados têm mais investimentos em infraestrutura, equipes e tecnologia, fato que se reflete nos serviços e produtos oferecidos por elas. Behr, Moro e Estabel (2008) explicitam sobre a importância da satisfação dos usuários, a partir dos serviços de qualidade e eficiência apresentada pela biblioteca escolar. Para tanto, sugerem que os serviços prestados sejam avaliados constantemente, a fim de conhecer a necessidade dos usuários.

Por fim, as bibliotecas foram avaliadas em relação aos recursos humanos, de acordo com os padrões do Grupo de Estudos em Biblioteca Escolar da Universidade Federal de Minas Gerais (CAMPELLO, 2010). Pelo padrão básico, as bibliotecas devem contar com um bibliotecário supervisor por grupo de bibliotecas, além de pessoal auxiliar em cada uma das bibliotecas e em cada turno. No nível exemplar, requer-se um bibliotecário responsável pela biblioteca e pessoal auxiliar em cada turno, em consonância, com a quantidade de estudantes. Os dados mostram que as bibliotecas C1, C2 e C4 foram avaliadas como exemplares. As bibliotecas dos colégios C3, C5 e C6 não obtiverem os requisitos mínimos, por isso, foram avaliadas no nível zero.

Quadro 8 - Avaliação dos recursos humanos das bibliotecas escolares

\begin{tabular}{|l|l|l|l|l|l|}
\hline C1 & C2 & C3 & C4 & C5 & C6 \\
\hline $\begin{array}{l}\text { Nível } \\
\text { exemplar }\end{array}$ & $\begin{array}{l}\text { Nível } \\
\text { exemplar }\end{array}$ & $\begin{array}{l}\text { Nível } \\
\text { básico }\end{array}$ & $\begin{array}{l}\text { Nível } \\
\text { exemplar }\end{array}$ & $\begin{array}{l}\text { Nível } \\
\text { zero }\end{array}$ & $\begin{array}{l}\text { Nível } \\
\text { zero }\end{array}$ \\
\hline
\end{tabular}

Fonte: Elaborado pelas autoras. 
Considerando a importância das bibliotecas escolares contarem com profissionais com formação especializada, a Lei da Biblioteca Escolar, Lei $n^{\circ}$ 12.244, de 24 de maio de 2010 (BRASIL, 2010) dispõe que as instituições de ensino públicas e privadas, de todos os sistemas de ensino do País, devem contar com bibliotecas escolares com a presença de um bibliotecário. A lei deve ser cumprida, efetivamente, até 24 de maio de 2020. Contudo, Gasque (2012) ressalta que, as bibliotecas atuantes como Centro de Recursos de Aprendizagem precisam ser espaços de incentivo à pesquisa, à leitura e à cultura. Isso requer a presença de um bibliotecário com boa formação e atitude para mudanças.

\subsection{Projetos de leitura e a contribuição da biblioteca escolar para a formação de competências leitoras}

Um dos objetivos específicos da pesquisa foi identificar os projetos de leitura das escolas pesquisadas e verificar a contribuição das bibliotecas escolares. A análise dos dados dos questionários-, respondidos por dezoito professores, mostra que as bibliotecas pesquisadas não participam ativamente dos planejamentos e do desenvolvimento das atividades de leitura. Vale ressaltar que as bibliotecas escolares devem cumprir papel essencial nesse processo, como menciona o documento Por las Bibliotecas Escolares de Iberoamérica. De acordo com o documento, a biblioteca escolar consiste de um espaço, por natureza, propício ao desenvolvimento das práticas de leitura e escrita, com possibilidade de dar suporte pedagógico e material para as várias áreas curriculares (CENTRO REGIONAL PARA EL FOMENTO DEL LIBRO EN AMÉRICA LATINA, EL CARIBE, ESPAÑA Y PORTUGAL, 2007).

Ainda, outro objetivo da pesquisa foi analisar a contribuição da biblioteca escolar para a formação de leitores. Verificou-se que os seis colégios pesquisados oferecem atividades de leitura sem muita interação com as bibliotecas. Além disso, observa-se que $72 \%$ dos docentes planejam as atividades de leitura para serem aplicadas separadamente em sala de aula, enquanto $28 \%$ dos docentes planejam as atividades de leitura, utilizando informação da biblioteca. Nesse sentido, não há planejamento de atividades em parceria com o bibliotecário, tampouco realização das atividades de leitura na 
biblioteca escolar.

Por sua vez, as poucas bibliotecas que oferecem tarefas de leitura centram-se nos estudantes do ensino fundamental e desenvolvem, na verdade, trabalho de animação da leitura. Isso significa que incentivam o gosto pela leitura, o uso do livro e da biblioteca, mas não desenvolvem competências leitoras.

Cuevas Cerveró (2007) e Naranjo (2005) diferenciam os termos animação da leitura e promoção da leitura. Animação da leitura refere-se à atividade que motiva os leitores e que possibilita a recreação mediante leitura de textos selecionados. A promoção da leitura, por sua vez, transcende a animação do livro e o uso da biblioteca, centrando-se no ensino de estratégias de leitura e fazendo uso da leitura compartilhada, por exemplo, para fortalecer as competências leitoras dos estudantes.

Outra questão importante, observada pelos resultados obtidos dos questionários, refere-se às atividades de leitura realizadas no ensino médio. Tais atividades são realizadas, em sala de aula, por todas as escolas pesquisadas e estão mais voltadas para a pesquisa e práticas para os vestibulares. Sobre isso, Santos (2011) explica que há anos o vestibular tem sido a referência do Ensino Médio, porém, agora, o Exame Nacional do Ensino Médio é responsável por estruturar o currículo desse nível de ensino. Dessa forma, o governo prepara a abolição do vestibular e toma o Exame Nacional do Ensino Médio como o natural sucessor. Santos (2011) argumenta que o Ministério da Educação pretende resolver o problema de parte do Ensino Médio, principalmente, nas escolas particulares, acusadas de atender às exigências dos vestibulares, por meio de conteúdos extensos e dissociados da realidade.

Quando questionados sobre o uso de estratégias leitoras utilizadas em sala de aula, de acordo os três espaços de tempo - "Antes da leitura", "Durante a leitura" e "Depois da leitura" -, os dados mostram que $95 \%$ dos professores usam a estratégia de formulação de hipóteses antes da leitura. Outros 90\% solicitam resumos após a leitura, e $85 \%$ releem com o auxílio de perguntas explícitas e inferenciais. Por fim, 75\% relatam ativar os conhecimentos prévios (quanto se sabe sobre o texto), enquanto $65 \%$ utilizam perguntas literais. 
Cantalice (2004) aborda o importante papel exercido pelo professor, ao propor modelos técnicos e procedimentos que proporcionem a compreensão da leitura. Ela explica que dentre as estratégias de leitura que podem ser conduzidas pelo professor estão: focalizar a atenção dos estudantes nas ideias principais; questionar os estudantes sobre o grau de compreensão da leitura; relacionar o conhecimento prévio dos alunos com nova informação; propiciar feedback para ajudar os estudantes a aplicarem técnicas e estratégias de estudo apropriadas; propiciar treinamento aos estudantes para usarem essas estratégias e técnicas de maneira mais efetiva; utilizar reforços positivos verbais e de escrita para estudantes com baixa compreensão; ajudar os estudantes a identificarem as contradições na compreensão do texto; e propiciar contato com vários tipos de textos em sala de aula. Ressalta-se que essas estratégias devem ser usadas desde as séries iniciais do ensino fundamental.

Em relação aos tipos de práticas de leitura em sala de aula e como se relacionam à construção de sentido do texto por parte do leitor, os resultados do questionário mostram que os tipos de leitura mais usados são a leitura-busca de informações e a leitura-fruição do texto, ambas com $90 \%$ de respostas e com frequência de uso semanal. No primeiro caso, o leitor extrai informações dos textos para responder as questões. No segundo, o objetivo é possibilitar o prazer de ler. Contudo, destaca-se que o "prazer de ler" é voltado para a leitura de livros de literatura para o vestibular. Antunes (2012) observou que esse tipo de prática de leitura em aula é a mais comum. A leitura é, basicamente, utilizada para a realização de tarefas, e as práticas são voltadas para a compreensão das ideias do autor do texto. Desse modo, não se proporciona à maioria dos estudantes a oportunidade de desenvolvimento do pensamento crítico.

Cesila (2009) questiona como o professor pode superar a incumbência de despertar o gosto pelos livros e, ao mesmo tempo, cumprir o conteúdo programático pré-estabelecido para cada ano do ensino médio. Acrescenta, também, que a lista de autores, escolas literárias e detalhes históricos, conteúdos de aprendizagem, em geral, estão distantes da realidade dos estudantes e podem gerar efeito contrário. A autora apresenta alternativas para tornar o ensino de leitura mais prazeroso, dentre elas, a leitura em conjunto com 
os estudantes, com o objetivo de buscar significado para as palavras difíceis; fazer uso de imagens - charges, tirinhas ou histórias em quadrinhos - como recursos auxiliares. Entretanto, a autora ressalta que o uso de tais estratégias não significa que o estudante deixará de ser colocado em contato com a obra original.

As propostas curriculares permitem também conhecer a configuração da leitura. Nos colégios particulares, observa-se que a proposta curricular, além de abranger as disciplinas tradicionais, incorporam outras que reforçam a aprendizagem da leitura. No Colégio $\mathrm{C} 1$, por exemplo, avaliado na quarta melhor posição do Brasil, no ranking do Exame Nacional do Ensino Médio de 2013, o currículo tem uma disciplina denominada "Interpretação de texto". No colégio C2, o segundo melhor do ranking do Exame Nacional do Ensino Médio 2013, do Distrito Federal, há o curso de "Redação" que se desenvolve desde a Educação Básica até o Ensino Médio. Da Educação Básica ao Ensino Fundamental II, há a promoção de atividades de leitura. Contudo, essas atividades são desenvolvidas pelos professores de língua portuguesa sem integração com a biblioteca.

Uma experiência, relatada por Gasque (2013), que pode inspirar os colégios, foi realizada pelo Colégio Marista de Brasília. Em geral, os primeiros projetos de fomento à leitura do colégio eram atividades pontuais ou projetos pessoais de alguns professores, por isso, investiu-se em um projeto comum e sistematizado, para formação do leitor, que consistiu de sete pontos:

a) desenvolvimento de estratégias diversificadas de leitura e compreensão de diferentes gêneros textuais em todas as disciplinas do currículo;

b) graduação do trabalho com gêneros e textos, em língua portuguesa, nas diferentes séries;

c) estabelecimento de metas literárias ao longo dos anos;

d) ampliação das habilidades (compreensão e rapidez) de leitura dos professores e estudantes;

e) expansão do vocabulário e melhoria da ortografia;

f) contato mais estreito com obras e autores diversificados da literatura infantil; 
g) ampliação do uso dos recursos e serviços do Centro de Recursos de Aprendizagem.

Adicionalmente, acrescenta-se aos sete pontos o monitoramento constante do processo, do trabalho dos professores e desempenho dos estudantes. Isso porque mesmo os melhores projetos podem ser deixados de lado na rotina corrida da vida escolar. Dessa forma, o projeto de leitura torna-se responsabilidade compartilhada pela comunidade educativa.

\subsection{Relação entre o docente e o bibliotecário nos projetos de leitura}

A pesquisa investigou a relação entre docentes e os bibliotecários das escolas, em relação aos projetos de leitura. Quase a metade dos docentes pesquisados (55\%) percebe a biblioteca escolar como espaço de aprendizagem, pesquisa, leitura e eventos culturais. Em seguida, $25 \%$ dos professores a veem como espaço de consulta de livros e documentos e, finalmente, um percentual de $20 \%$ a veem como espaço de promoção da leitura. Verificou-se a ausência de trabalho integrado entre docentes e bibliotecários, em relação aos projetos de leituras. As atividades que, em geral, são desenvolvidas em parceria entre biblioteca escolar e professores são os projetos de pesquisa e os eventos da escola, além da seleção de materiais para a biblioteca. Contudo, somente seis dos 18 professores pesquisados usam os recursos da biblioteca escolar.

As hipóteses principais para explicar esses resultados são: a cultura tradicional do professor e da própria escola, assim como a grande quantidade de conteúdo do currículo que impede a realização de tarefas que requerem mais tempo. De acordo com Gasque e Costa (2003), tradicionalmente no Brasil, o livro didático ainda é a fonte de informação mais usada em sala de aula. Essa forte vinculação com o livro didático ocorre devido à rotina e à forte tradição pedagógica a qual os professores estão submetidos. Nessa perspectiva, o livro didático atua como espinha dorsal de quase todos os componentes curriculares. Isso faz com que os professores não busquem outros materiais e, consequentemente, não percebam a necessidade de usar a biblioteca.

Ainda, sobre a questão do uso das bibliotecas, o relatório de Avaliação das Bibliotecas Escolares no Brasil (2011), promovido pelo Ministério da 
Educação do Brasil, em parceria com a Organização dos Estados IberoAmericanos e com a Agência Espanhola de Cooperação Internacional para o Desenvolvimento, reconhece a necessidade de os professores desenvolverem o gosto pela leitura e incorporarem a utilização da biblioteca em suas aulas. Ressalta, assim, que não adianta existirem bibliotecas que não são utilizadas.

Um ponto que pode fortalecer a relação professores/biblioteca escolar é a formação do professor. O professor precisa conhecer o espaço, o acervo e identificar as possibilidades de parceria com o bibliotecário. Imbernón (1994) argumenta que a formação do professor deve ocorrer em sintonia com a forma como o professor deve ensinar. Assim, se o docente aprende a usar os recursos da biblioteca e consegue perceber como eles podem maximizar a aprendizagem dos estudantes, há mais chances de incorporar o uso desses recursos nas atividades de ensino-aprendizagem.

Outro fator importante para que haja integração entre docentes e a biblioteca escolar é a presença de bibliotecários e recursos humanos em quantidade suficiente para realizar as atividades. Nos três colégios particulares, as bibliotecas estão a cargo de bibliotecários, mas nos colégios públicos não há bibliotecários. Também, é importante destacar que, em todos os colégios, a quantidade de funcionários que realizam trabalhos nas bibliotecas escolares não é compatível com a quantidade de estudantes.

No que concerne à formação dos bibliotecários, é necessário que as faculdades de biblioteconomia revejam o próprio currículo e incluam disciplinas voltadas para a biblioteca escolar e questões psicopedagógicas. Com certeza, a ausência de conhecimentos básicos influencia a atuação dos bibliotecários escolares.

Ao tratar da percepção dos professores sobre a contribuição da biblioteca escolar para os resultados do Enem, observou-se que, apesar de vários problemas, a percepção é positiva. Os professores avaliaram positivamente o horário amplo de atendimento (37\%) e a presença de funcionários competentes no atendimento aos estudantes (27\%), coleção atualizada (24\%) e atendimento (18\%), fatores que influenciam nos resultados do Enem. 
Pode-se inferir pelos resultados obtidos na pesquisa que as bibliotecas escolares influenciam na aprendizagem. Outras pesquisas também mostram resultados similares: Williams, Wavell e Morrison (2013), por exemplo, realizaram, na Escócia, uma pesquisa para identificar e avaliar as evidências disponíveis sobre a influência das bibliotecas escolares na aprendizagem. Os resultados revelam a existência de um considerável corpo de evidências que demonstram que as bibliotecas escolares contribuem positivamente na aprendizagem.

\section{Conclusões e recomendações}

A pesquisa buscou analisar a contribuição das bibliotecas escolares nos resultados do Exame Nacional do Ensino Médio, considerando os projetos de leitura. Em síntese, os resultados apontaram que os colégios apresentam estrutura adequada (salas de aulas, espaços de lazer, etc.), ainda que haja diferenças grandes entre os particulares e os públicos, em especial, no que concerne à presença das novas tecnologias. As escolas apresentam concepção pedagógica renovada, pelo menos, no discurso. No entanto, apesar de algumas disciplinas complementares no currículo, o ensino-aprendizagem ainda parece ser mais tradicional.

As estruturas das bibliotecas ainda se encontram no patamar básico ou menos: as bibliotecas possuem o mínimo de computadores necessários ao funcionamento, mas não em quantidade suficiente para os estudantes. Foram bem avaliados os acervos, pelo menos, quantitativamente, e os catálogos das bibliotecas, mas os serviços oferecidos são básicos. Além disso, apesar de metade das bibliotecas contarem com um bibliotecário, a quantidade é insuficiente ao se considerar o número de estudantes.

Os resultados mostram que os projetos de leitura vinculados às disciplinas, em geral, são realizados sem a participação das bibliotecas escolares. Contudo, os professores relataram que as bibliotecas escolares contribuíram para o resultado do Enem em outros aspectos, tais como, oferecer acesso à informação organizada e aos recursos humanos e propiciar horário de atendimento adequado. 


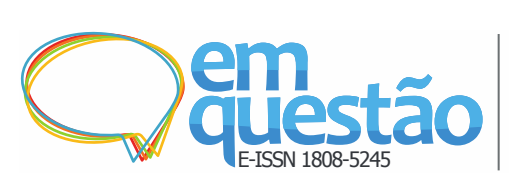

Por fim, os dados mostram que os professores têm uma concepção abrangente de biblioteca no discurso, mas isso não se traduz em termos práticos. Além disso, em relação às atividades de leitura em sala de aula, as estratégias ensinadas aos estudantes são as básicas. Os tipos de leitura praticados são a busca de informação e a leitura por prazer, que no caso, vinculam-se aos estudos literários necessários ao vestibular ou à avaliação do Enem.

Retomando a pergunta de pesquisa, observa-se que as bibliotecas escolares não contribuíram diretamente para o resultado do Enem, em relação aos projetos de leitura, porém, contribuíram indiretamente por meio dos serviços e produtos oferecidos. As bibliotecas pesquisadas não podem ser consideradas Centros de Recursos de Aprendizagem e não ocupam papel de protagonismo na escola. Portanto, o pressuposto de que o desenvolvimento da competência leitora no processo de letramento informacional, realizada nas bibliotecas escolares, em parceria com os docentes, influencia positivamente a aprendizagem dos estudantes não se confirmou nas bibliotecas pesquisadas.

Nesse sentido, pode-se perceber que o espaço físico e o acervo podem ser ampliados e atualizados. Contudo, o mais importante diz respeito à mudança de cultura pedagógica. A comunidade acadêmica precisa, realmente, se conscientizar de que a biblioteca escolar pode desempenhar papel crucial na aprendizagem, desde que atue como Centro de Recursos de Aprendizagem, integrado ao currículo da escola. As escolas, por sua vez, precisam ter um currículo mais flexível e voltado para a resolução de problemas. Para que isso ocorra, a formação dos professores e do bibliotecário torna-se elemento essencial, visto que esses profissionais carecem de capacitação, recursos e estratégias para realmente propiciar aprendizagem mais significativa.

No que concerne à leitura, as atividades de animação e promoção da leitura, realizadas nas escolas pesquisadas são consideradas concepções restritas, que precisam ser ampliadas. Acredita-se que, nos primeiros anos da escola, deveriam consolidar-se as competências leitoras, estimular o gosto pela leitura e, nos anos seguintes, reforçar essas práticas com atividades de desenvolvimento das competências leitoras voltadas para o pensamento crítico. 
Apesar de as escolas apresentarem, pelas propostas pedagógicas, a importância da leitura, na prática, mostram lacunas no planejamento e na formação de mediadores para que realmente ajudem os estudantes a desenvolverem as competências leitoras. Nessa perspectiva, as bibliotecas atuam como atores secundários ou quase inexistentes. Por isso, é necessário o respaldo da proposta pedagógica e o monitoramento para que isso ocorra efetivamente em sala de aula.

Assim, sugere-se um esquema de trabalho para o planejamento de atividades de leitura integradas ao currículo:

Figura 2 - Processo de projeto de leitura

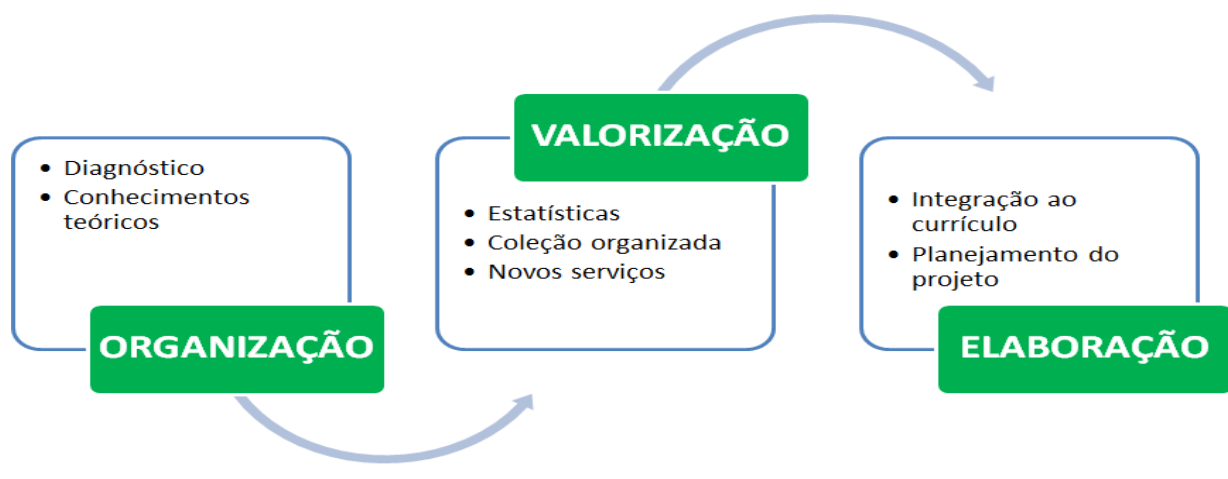

Fonte: Elaborada pelas autoras.

A figura mostra a existência de três fases, quais sejam a organização, a valorização e a elaboração. A organização abrange o diagnóstico e os conhecimentos teóricos necessários ao projeto de leitura. Nessa fase, requer-se conhecer infraestrutura, tipo de coleção, serviços, projetos, recursos humanos, financeiros e parcerias. Além disso, é importante conhecer o paradigma subjacente à concepção da biblioteca. A fase da valorização vincula-se à imagem que a biblioteca reflete. Por isso, a análise dos dados estatísticos e a organização do acervo permitem que se implementem serviços adequados ao perfil e às necessidades da comunidade educacional. Finalmente, a elaboração corresponde ao esboço e à apresentação desses resultados e da ideia aos professores, bem como a plena participação dos professores na elaboração do 
projeto, na definição de objetivos, metas, programação das atividades, avaliação e monitoramento.

As bibliotecas escolares das instituições públicas mostram falta de infraestrutura, equipamentos, computadores e pessoal qualificado. As bibliotecas escolares da rede pública pesquisadas não contam com bibliotecários. No entanto, esse fato por si só não assegura a qualidade das bibliotecas, como se verificou pela presença de bibliotecário nas bibliotecas das escolas privadas. Existem outros elementos que influenciam no êxito da biblioteca como: a concepção pedagógica, o tipo de currículo, a quantidade de conteúdos acadêmicos, a formação dos educadores, dentre vários outros. Assim, é necessário verificar mais profundamente os fatores que impedem a plena integração da biblioteca à estrutura pedagógica.

Um aspecto que pode influenciar positivamente na formação dos bibliotecários é a mudança do currículo das faculdades, assegurando que os graduandos cursem disciplinas obrigatórias voltadas para atuação nas bibliotecas escolares. Os cursos de pedagogia e licenciatura, por sua vez, de maneira geral, precisam proporcionar disciplinas e cursos que ensinem os estudantes a usarem os recursos de informação e a desenvolverem as estratégias de leitura, independente da área, por exemplo, química, matemática, dentre outros. Isso porque a leitura é responsabilidade de todos os membros da sociedade.

\section{Referências}

ANTUNES, J. S. C. Leitura, compreensão e formação do leitor. In: ENCONTRO NACIONAL DE DIDÁTICA E PRÁTICAS DE ENSINO, 16., 2012, Campinas. Didática e práticas de ensino na realidade escolar contemporânea. Anais... Araraquara: Junqueira\&Marin, 2012. Disponível em: <http://www.infoteca.inf.br/endipe/smarty/templates/arquivos_template/upload_ arquivos/acervo/docs/2338d.pdf>. Acesso em: 29 jan. 2015.

AVALIAÇÃO das bibliotecas escolares no Brasil. São Paulo: Edições SM, 2011. Disponível em: <http://www.oei.es/bibliobrasil.pdf>. Acesso em: 4 jan. 2015.

BEHR, A.; MORO, E. L. S.; ESTABEL, L. B. Gestão da biblioteca escolar: metodologias, enfoques e aplicação de ferramentas de gestão e serviços de biblioteca. Ciência da Informação, Brasília, v. 37, n. 2, p. 32-42, ago. 2008. 
BRASIL. MEC e Inep comentam resultados do Enem 2014. 2015. Disponível em: <http://www.brasil.gov.br/educacao/2015/01/mec-e-inep-apresentamresultados-do-enem-2014>. Acesso em: 12 fev. 2015.

BRASIL. Ministério da Educação. Instituto Nacional de Estudos e Pesquisas Educacionais Anísio Teixeira. Exame Nacional do Ensino Médio: documento básico. Brasília, 2002. Disponível em:

<http://portal.inep.gov.br/documents/186968/484421/ENEM+-

+ Exame+Nacional+do+Ensino+M\%C3\% A9dio+documento+b\%C3\%A1sico+2 002/193b6522-cd52-4ed2-a30f-24c582ae941d?version=1.2>. Acesso em: 9 jan. 2017.

BRASIL. Senado Federal. Lei 12.244, de 24 de maio de 2010. Dispõe sobre a universalização das bibliotecas nas instituições de ensino do País. Diário Oficial [da] União, Brasília, 25 maio 2010. Disponível em:

<http://www.planalto.gov.br/ccivil_03/_Ato2007-2010/2010/Lei/L12244.htm> Acesso em: 30 jan. 2015.

CAMPELLO, B. (Coord.). Biblioteca escolar como espaço de produção de conhecimento: parâmetros para criação e avaliação de bibliotecas escolares. Belo Horizonte: GEBE, 2010.

CANTAliCE, L. M. Ensino de estratégias de leitura. Psicologia Escolar e Educacional, Campinas, v. 8, n. 1, p. 105-106, jun. 2004.

CARVALHO, M. C. Escola, biblioteca e leitura. In: CAMPELLO, B. et al. A biblioteca escolar: temas para uma prática pedagógica. Belo Horizonte; Autêntica, 2008.

CENTRO REGIONAL PARA EL FOMENTO DEL LIBRO EN AMÉRICA LATINA, EL CARIBE, ESPAÑA Y PORTUGAL. Por las bibliotecas escolares de iberoamérica. Colombia, 2007.

CESILA, J. S. da S. O ensino de literatura no ensino médio: uma tentativa de aliar o conhecimento ao prazer da leitura. In: CONGRESSO DE LEITURA DO BRASIL, 17., 2009, Campinas. Anais... Campinas: ALB, 2009.

CUEVAS CERVERÓ, A. Lectura, alfabetización en información y biblioteca escolar. Gijón: Trea, 2007.

FREIRE, P. A importância do ato de ler. São Paulo: Moderna, 2003.

GALLARDO, S. C. H. El constructivismo social como apoyo en el aprendizaje en línea. Apertura, Guadalajara, v. 7, n. 7, p. 46-62, nov. 2007.

GASQUE, K. C. G. D. Arcabouço conceitual do letramento informacional.

Ciência da Informação, v. 39, n. 3, p. 83-92, set./dez. 2010. 
GASQUE, K. C. G. D. Centro de Recursos de Aprendizagem: biblioteca escolar para o século XXI. RDBCI: Revista Digital de Biblioteconomia e Ciência da Informação, Campinas, v. 11, n. 1, p. 138-154, jan. 2013. Disponível em: <http://periodicos.sbu.unicamp.br/ojs/index.php/rdbci/article/view/1656>. Acesso em: 31 jan. 2013.

GASQUE, K. C. G. D. Letramento informacional: pesquisa, reflexão e aprendizagem. Brasília: Faculdade de Ciência da Informação, 2012.

GASQUE, K. C. G. D.; COSTA, S. M. de S. Comportamento dos professores da educação básica na busca da informação para formação continuada. Ciência da Informação, Brasília, v. 32, n. 3, p. 54-61, dez. 2003.

HOPKINS, D. M. The School Library Collection: an essential building block to teaching and learning. School Libraries Worldwide, Tallahassee, v. 5, p. 1-15, 1999.

IMBERNÓN, F. La formación del profesorado. Buenos Aires: Paidós, 1994.

INTERNATIONAL FEDERATION OF LIBRARY ASSOCIATIONS AND INSTITUTIONS. Directrizes da IFLA/UNESCO para bibliotecas escolares. 2002. Disponível em: <https://www.ifla.org/files/assets/school-librariesresource-centers/publications/school-library-guidelines/school-libraryguidelines-pt.pdf>. Acesso em: 16 mar. 2013.

INTERNATIONAL FEDERATION OF LIBRARY ASSOCIATIONS AND INSTITUTIONS (IFLA). Manifesto UNESCO-IFLA para biblioteca escolar. 2000. Disponível em: <http://www.ifla.org/files/assets/school-libraries-resourcecenters/publications/school-library-guidelines/school-library-guidelines-es.pdf>. Acesso em: 16 mar. 2013

KUHLTHAU, C. C. O papel da biblioteca escolar no processo de aprendizagem. In: VIANNA, M. M.; CAMPELLO, B.; MOURA, V. H. V. Biblioteca escolar: espaço de ação pedagógica. Belo Horizonte: EB/UFMG, 1999, p. 9-14.

MORENO, V. Lectura de prensa y desarrollo de la competencia lectora. Madrid: Ministerio de Educación, Secretaria General de Educación y Formación Profesional, 2009.

NARANJO, V. E. ¿Debe tener bases pedagógicas el bibliotecólogo dedicado a la promoción de la lectura? Revista Interamericana de Bibliotecología, Medellín, v. 28, n. 1, p. 113-145, jan./jun., 2005.

POZO, J. Aquisição de conhecimento: quando a carne se faz verbo. Porto Alegre: Artmed, 2004.

QUAGLIA, I.; BONNICI, C. G. A.; PAIXÃO; P. C. M. Formação leitora dos alunos do ensino superior: análise da construção desse processo. Espaço 
Pedagógico, Passo Fundo, v. 22, n. 1, 2015. Dispoível em: <http://seer.upf.br/index.php/rep/article/view/5191/79-90>. Acesso em: 9 jan. 2017.

SANTOS, J. M. C. T. Exame Nacional do Ensino Médio: entre a regulação da qualidade do Ensino Médio e o vestibular. Educar em Revista, Curitiba, n. 40, p.195-205, jun. 2011.

SANTOS, F. et al. (Org.) Mediação de leitura: discussões e alternativas para a formação de leitores. São Paulo: Global, 2009.

SOLÉ, I. Competencia lectora y aprendizaje. Revista Iberoamericana de Educación, Madrid, n. 59, p. 43-61, 2012.

SOLÉ, I. Estratégias de lectura. Barcelona: GRAO, 2004.

WILLIAMS, D.; WAVELL, C.; MORRISON; K. Impact of school library: critical review of published evidence to inform the work of the Scottish education community. Aberdeen: Robert Gordon University, 2013.

\title{
Reading as information literacy in school libraries
}

\begin{abstract}
The article analyses the contribution of reading projects at school libraries from schools that obtained the first places in the 2013 ranking of Enem. The specific objectives are: description of the pedagogical proposal and structure of the schools; description of the structure, the products and the services offered by the school libraries; identification of reading projects and its contribution to the development of reading skills, and finally, identification of the relationship between teachers and librarians in the reading projects. The methodology presents a quali-quantitative nature. The sample focused in six schools, three private and three public. The results show that the reading projects linked to the school subjects, in general, are carried out without the participation of school libraries. However, teachers reported that school libraries have contributed to the result of Enem in certain ways, such as providing access to information and human resources and good space and time to attend students.
\end{abstract}

Keywords: School Library. Learning Resource Center. Reading. Reading Skills. Enem.

Recebido em: 05/10/2016

Aceito em: 21/01/2017 